\title{
Organizational survival: The effects of leadership skill and strategy
}

\author{
Kehinde James Sunday ${ }^{1}$, Idris Adekunle ${ }^{1}$, Oluitan Roseline ${ }^{2}$ \\ ${ }^{1}$ Dept of Accounting and Finance, Lagos State University Ojo \\ ${ }^{2}$ Dept of Business Administration and Mgt Tech, Lagos State University Ojo
}

Email address:

pastorkehindebox@yahoo.com(K. J. Sunday)

\section{To cite this article:}

Kehinde James Sunday, Idris Adekunle, Oluitan Roseline. Organizational Survival: The Effects of Leadership Skill and Strategy. Science Journal of Business and Management. Vol. 2, No. 2, 2014, pp. 44-49. doi: 10.11648/j.sjbm.20140202.11

\begin{abstract}
Leadership remains the art of corporate organization. It is the most important factor in the survival and the growth of the firm. The continuing existence of the firm depends on the leadership of the firm; and too often than not, leaders do believe that their strategy and policy coupled with their ability get them the success they are experiencing without looking at the impact of the environmental factor and other externalities. They often do not review while they succeed but do often examine why they fail. The study made use of factor analysis:-The principal component analysis; Total Variance Explained and the chi square were used. The study revealed that there is a relationship between leadership and organization success. It was recommended that organization leadership should take into consideration factors within the firm and outside the firm that can increase or inhibit the firm's success.
\end{abstract}

Keyword: Success, Leader, Strategy, Failure

\section{Introduction}

Globally, leadership has become the most widely studied aspect of organizational behaviour and a number of theories have emerged focusing on the strategies, traits, styles and the situational approach to leadership. As a result of evergrowing interest in the field of leadership, behavioural scientists and sociologists began to analyze the possible consequences of leadership behaviour and the variables that are used to predict the leader's behaviour. Since it is the duty of leaders to get things done through the coordinated efforts of others, it is assumed therefore that leadership strategies will translate into the subordinates' performance and the achievement of success by the firm. Strategies here represent the actions that are taken by the leader to accomplish objectives (Oghojafor, 2007. Horner, 2002 . Rollinson, 1998). The objectives of the firm are usually stated in terms of growth in assets, growth in sales, profitability, market share, nature of diversification, nature of vertical integration, earnings per share and social responsibility (Kehinde, 2011). All these objectives indicate whether the firm is successful or not, thus, the word 'success' in this study would connote the achievement of these goals.

In business organization, the effects of leadership on the achievement of the goals(here called success) of the firm remain not measurable there is the problem of how to measure the effect of leadership(top executives) influence, personality, style and ego on the firms long term success. most leaders believe that their organizational success depends on their ability and strategy without the influence of external factors. Over time the leader becomes overconfidence and overbearing with the acquisition of more powers within the firm and with time the leader soon failure that is the fortune of the firm soon dwindle with the same leader who had help the firm achieve success before . Thus there is the problem of why the same leader who had led the firm to major success over time suddenly leads the same firm to failure after some times. Thus this work is out the study this problem and how slove it the problemis what I often refers to "as the hollow of leadership success" or "the success-breeds-failure trap" according to Cookery (2011).

\section{Objectives of the Study}

The major objective of this study is to evaluate reasons for the success and failure of leaders in business organization over time.

The specific objectives include the following: 
(1) To determine the impact of leaders' skills and strategies on organization survival or success.

(2) To evaluate the relationship between leaders managerial skills and organization performance.

(3)To establish the strategies adopted by leaders to actualise their organisation goals.

\section{Literature Review}

Leadership is a process by which an individual influences the thoughts, attitudes, and behaviours of others. The Leaders set a direction for the firm; they help see what lies ahead; they visualize what they might achieve and how to achieve it; they encourage and inspire the subordinates (Quinn, 2005).

Leadership is therefore very important to the survival and effectiveness of organization's performance. As organizations grow, the expectations about their performances increase and demand for good leadership tends to multiply. Leadership ability is a valuable skill and those who possess it reap high rewards. Therefore, from every indication, there is a strong link between leadership strategies and survival of the organization. However, most leaders tend to learn more from failure than from success, notwithstanding failure and success of the firm are two sides of the same coin source?. The issue is that leaders so often ask the question "why do we fail" than to ask for "why the success they experience occurred". They take for granted the effect of today's success on the future performance of the firm.

The basic problem in leadership of the corporate organization is that leaders do quickly asked why the failure, than to ask why the successes. However, today's success could bring about tomorrow's failure, if the firm refused to learn from success as they would have learnt from failure. The objective of this study therefore is to examine why successful leaders in corporate organization soon fall prey of failure while leading the same firm over a period of time. They experience success and all too often slip into failure that sometimes erodes the glamour of the success they have enjoyed over the years. Source

Cole (2005) defines Leadership as personal hero. He states that the leader is an individual hero; a leader is a strong-willed and charismatic chief executive who personifies an organization and its success.

Margie (2012) agrees that there is an increasing demand for excellent leaders. With globalization, the improvements in technology, a changing workforce and the changing expectations and values of workers, come more challenging contexts in which to lead agreed and without good leadership, organizations move too slowly, stagnate and lose their way (Margie,2012)

Margie (2012) proves in a study on leadership and commitment that a positive correlation exits between the construct of effective commitment and the construct of transformational leadership. Unquestionably, the constituents of transformational leadership are conducive to the development of affective commitment. The findings indicate that transformational leadership has tremendous potential to influence employee motivation, performance and affective commitment.

Bass (1994) offers an insight into the dimensions of transformational leadership and the relationship between transformational leadership and decision making and team spirit. Kotter (2012) itemized eight stages and process to follow when leading for change; and this includes that ability of the leader to measure why the firm fails and succeeds.

Perkins (2003) identifies four different patterns or "archetypes" or types into wish leadership styles might be categorized this includes: Answer-Centered Leadership type which emphasis what's to be done and why, this leadership style emphasis the leader given directive from the top of an organization. Secondly, there is the VisionCentered Leadership style: this offers a strong energizing vision about the general direction of an organization, along with great personal commitment. Thirdly, there is the Inquiry-Centered Leadership which fosters inquiry at various levels through questions, facilitation, and establishing community and organizational structures supportive of inquiry. Fourthly, there is the Leadership by Leaving Alone style : this style of leadership believes in leaves people alone to find their way. This approach reveals the personnel who have what it takes to survive and assume roles with increasing responsibility to earn the organization the required success.

Gino and Gray (2011) on the other hand study the relationship between organization leadership and the reason for organization success. And concluded that leadership style do influence the success of the firm, that is, the achievement of the organizational goals and objectives

However, most of the studies reviewed on why leaders succeed revealed that success can breed failure by hindering learning at both the individual and the organizational level. Learning from failure is one of the most important capacities for people and companies to develop. Learning from success can present even greater challenges. The success-breeds-failure trap could be avoided by learning from success, as well as from failure (cookery, 2011).

Steven (2011) notes that it is all too common for executives to attribute their organization success to their own insights and managerial skills and downplays random events or external factors outside their control that make for the success of the firm they lead.

Quinn (2005) states that an individual willing to take a leadership position must have a vision about what he wants to accomplish. He must make a commitment to the mission and to the people he wants to lead. He must take responsibility for the accomplishment of the mission and the welfare of the people he is leading. The leader will also be willing to assume responsibility for risk of loss and failure and accept recognition for success.

In measuring the relationship between leadership training 
and effectiveness, Horner (2002) states that executive coaching is very effective in training and developing leadership skill in the subordinates he also noted that executive coaching is effective in enhancing organisation financial performance. He-who? Further states that financial investment on executive coaching as a way of developing leaders in the firm is of value and worth it thus in achieving success that is the achievement of the organic goals of the firm executive coaching should be considered a strong factor.

\section{Methodology}

This study made use of the survey research design, the population of the study is the staff of four major firms these are Cadbury Nigerian plc, Doyin group of companies, zenith bank plc, and Access Bank plc and five universities top executive and top academician in the field of management and the social science in Nigeria. These firms were selected based on their capital base and market share in their industry using the personal knowledge of the researcher. The most capitalized and the least capitalized firms were those chosen or selected for fair sample, the total sampling frame remains 300 . The study made use of primary data that were generated through a survey using questionnaire. From the corporate organization and the academics a total of 75 samples were selected. Thus, total of 35 top executives from the rank of senior managers and above were selected using simples random sampling form the business organization. From the Universities, the academic staff from the rank of Senior Lecturer and above were those selected as the respondents using simple random sampling, a total of 35 respondent were selected from total sampling frame. The total sample therefore remains eighty (75).(see figure 1) Our goal is to have equal respondents from both the academic and the business organisation. The questionnaire used sought the opinions of the top executives and the academics on issues bordering on leadership skills and strategy in relation to organizational success and survival. The questionnaire was designed using a five point scales from strongly agreed to strongly disagreed with value ranging from 5 to 1

Figure 1

$\mathrm{N}$

$\mathrm{n}=\quad 1+\mathrm{N}(\mathrm{e})^{2}$

where: $\mathrm{n}=$ number of samples

$\mathrm{N}=$ number of population (300)

$\mathrm{e}=$ standard error of sampling is still tolerated, which is

$10 \%$ for $90 \%$ confidence level.

$\mathrm{n}=75$

For the data analysis, Principal Components Analysis (PCA) was used. PCA is a useful statistical technique used in selecting high value variables and that with strong appeal in research; it is therefore useful in selecting major constructs in research having several concepts. The selected variables or construct will be tested in the study.

In principal component analysis, one of the most commonly used criteria for solving the number-ofcomponents problem is the eigen value-one criterion, also known as the Kaiser criterion (Kaiser, 1960). With this approach, one retains and interprets any component with an eigenvalue greater than 1.00 . The rationale for this criterion is straightforward. Each observed variable contributes one unit of variance to the total variance in the data set. Any component that displays an eigenvalue greater than 1.00 is accounting for a greater amount of variance than those ones contributing one to the set. Such a component is therefore accounting for a meaningful amount of variance, and is worthy of being retained. On the other hand, a component with an eigenvalue less than 1.00 is accounting for less variance than those contributing above 1.00 to the set. For this reason, components with eigenvalues less than 1.00 are viewed as trivial, and are not retained among selected set. Stevens (1986) reviews studies that have investigated the accuracy of the eigenvalue-one criterion, and recommends its use when less than 30 variables are being analyzed and communalities are greater than 0.70 , In this study therefore, principal component analysis (PCA) was utilized to determine the important factors explaining leadership skill and strategies. This deviates from the traditional approach of regressing leadership skill and strategies on some selected organization survival correlates. The hypotheses were also tested with the usage of the chisquare. And the mean ranking was used for the variables selected. Where did the hypotheses come from? The study does not have a justification, objectives, questions/hypotheses, scope and significance.

\subsection{Key to Variables}

The variables used in the study is hereby stated below the various keys

Var001: Executive attributes the success of their organizations to their own insights and managerial skills and ignores or downplays random events or external factors outside their control

Var002: Executives over confidence inspired by past success can infect the whole organizations

Var003: Success is commonly interpreted as evidence not only that the executives' existing strategy and practices work but also that you have all the knowledge and information needed

Var004: Executive should celebrate success but examine why it occurred.

Var005: Organization leadership should institute a system project review using the "After-action reviews" strategy.

Var006: Organization leadership have appropriate time frame for evaluating performance in order to avoid misconstructing the factors that led to success or failure.

Var007:Top executives should institute "a-phase, a system process of classify factors that make for success as "internal and external factors"

Var008: The right question for leaders of learning 
organizations to ask is not "what are we doing well" but rather "what experiments are we running"

Var009: Successful executives over time soon fall prey of success syndrome "The tendency that I am the best, I cannot fail" and enhance failure soon occurred.

Var0010: The more power the chief executive acquired by time and by success-stories the more solo-mind they become.

Var00 11: Top executives often fall prey of power syndrome and the feeling of I know it all and Often failure soon erupts.

\section{Empirical Results}

The data analysis is presented here. The variables are first states and the PCA was then used in the selection of the most value one. The selected set forms the constructs of the study and were subsequently tested using the chi-square technique

\subsection{Results of Descriptive Statistics}

Table 1: Mean ranking of leadership style and strategies

\begin{tabular}{|c|c|c|c|}
\hline & Value & Mean & Rank \\
\hline Var 005 & & 4.8 & $1^{\mathrm{st}}$ \\
\hline Var 006 & & 4.6 & $2^{\text {nd }}$ \\
\hline Var 004 & & 4.6 & $3^{\text {rd }}$ \\
\hline Var 007 & & 4.4 & $4^{\text {th }}$ \\
\hline Var 003 & & 4.1 & $5^{\text {th }}$ \\
\hline Var 008 & & 4.0 & $6^{\text {th }}$ \\
\hline Var 009 & & 3.8 & $7^{\text {th }}$ \\
\hline Var 0010 & & 3.8 & $8^{\text {th }}$ \\
\hline Var 009 & & 3.8 & $9^{\text {th }}$ \\
\hline Var 002 & & 3.2 & $10^{\text {th }}$ \\
\hline Var 001 & & 3.6 & $11^{\text {th }}$ \\
\hline
\end{tabular}

Source: SPSS output

From the above mean ranking, it is discovered that the first five variables were accepted as very significant using the arithmetic average of 4.1 , the first five variables which are;

i. Organization leadership should institute a system project review using the after action review strategy.

ii. Organization leadership have appropriate time frame for evaluating performance in order to avoid mis-constructing the factor that led to success or failure.

iii. Executive should celebrate success but examine why it occurred.

iv. Top executives should institute a phase, a system process of classifying factors that make for success as internal and external factors.

The above variables rank most significant and in order of value to organization leadership performance style. They are considered germane to top executive success in the organization and are critical issues of consideration for top leadership style need.

\subsection{Result of Principal Component Analysis}

Principal component analysis (PCA) retained 4 out of a possible 11 leadership style and strategy variables. The variables were var001, var002, var003, and var004. Var001 showed a high correlation to organizational survival. This justified the use of expenditure as a proxy for poverty. The Kaiser-Meyer-Olkin Measure (KMO) of sampling adequacy is a measure for comparing the magnitudes of observed correlation with the magnitudes of partial correlation coefficients. The value of the KMO is 0.604 and this showed the appropriateness of the model which is within an acceptable range for a well-specified model (Table 2). The value of Bartlett ${ }^{\text {ec }} \mathrm{s}$ test of sphericity is 1 and the associated level of sphericity is 0.05 .

Table 2: KMO and Bartlett's Test

\begin{tabular}{lc|l}
\hline Kaiser-Meyer-Olkin Measure of Sampling & \\
Adequacy. & & .604 \\
Bartlett's $\quad$ Test & of Approx. Chi-Square & 7183.693 \\
Sphericity & Df & 120 \\
& Sig. & .000 \\
\hline
\end{tabular}

The latent rule criterion was used to determine the number of factors. There are 4 factors with latent roots greater than one; the rule suggests 4 factor solution for our data. The total variation in the data explained by the 4factor solution was $81.451 \%$.

The Eigen values for the 4 - factors are contained in Table 3. There is no difference between the extracted sum of squared loading and rotation sum of squared loading so they all add up to the same value of $81.451 \%$. The size of an eigenvalue indicates the amount of variance in the principal component explained by each component

Factor 1 has the highest extraction sum of squared loading of 3.437 representing $31.247 \%$ and also the highest score of rotation sum of squared loading of 2.547 representing $23.157 \%$ for our respondents. Factor 4 has the least on both extracted and rotation sum of squared loading with 1.372 accounting for $12.477 \%$ and 1.595 representing $14.504 \%$ respectively for our respondents. Table 3

The results indicate that no factor is considered redundant with rotated and un-rotated solutions. The sum of squared loadings for the other factors fall between the ranges described above. The contributing power of the factors to the explanation of the variance in the variables is considered significant. 
Table 3a: Total Variance Explained

\begin{tabular}{lllllll}
\hline Component & \multicolumn{2}{l}{ Initial Eigen Value } & \multicolumn{3}{l}{ Extraction Sums of Squared Loadings } \\
& Total & \% of Variance & Cumulative \% & Total & \% of Variance & Cumulative \% \\
\hline 1. & 3.437 & 31.247 & 31.247 & 3.427 & 21.247 & 31.247 \\
2. & 2.330 & 21.178 & 52.425 & 2.330 & 16.549 & 68.974 \\
3 & 1.820 & 16.549 & 68.974 & 1.820 & & \\
4. & 1.372 & 12.477 & 81.451 & 1.372 & & \\
5. & .995 & 9.041 & 90.493 & & & \\
6. & .432 & 3.927 & 94.419 & & & \\
7. & .351 & 3.189 & 97.607 & & & \\
8. & .180 & 1.634 & 99.243 & & & \\
9. & .083 & .757 & 100.000 & & & \\
10. & $-4.971 \mathrm{E}-16$ & $-4.519 \mathrm{E}-15$ & 100.000 & & & \\
11. & $-6.074 \mathrm{E}-16$ & $-5.522 \mathrm{E}-15$ & 100.000 & & & \\
\hline
\end{tabular}

Extraction Method: Principal Component Analysis

Table 3b: Total Variance Explained

\begin{tabular}{llcl}
\hline Component & \multicolumn{3}{l}{ Rotation Sums of Squared Loadings } \\
\hline & Total & \% of Variance & Cumulative \% \\
1. & 2.547 & 23.157 & 23.157 \\
2. & 2.523 & 22.932 & 46.090 \\
3. & 2.294 & 20.857 & 66.947 \\
4. & 1.595 & 14.504 & 81.451 \\
5. & & & \\
6. & & \\
7. & & \\
8. & & \\
9. & & \\
10. & & \\
11. & & & \\
\hline
\end{tabular}

Extraction Method: Principal Component Analysis

The orthogonal rotated solution was chosen to obtain uncorrelated components using varimax Kaiser Normalization rotation method. The rotated component matrix of PCA led to the selection of four components explaining leadership style. These components reflect leadership style thorough different indicators as follows:

Factors 1 , factors 2 , factor 3, factor 4 which loaded 4 variables except factor 4 that loaded 2 variables of the loaded variables $0.954,0.882,0.879$ and 0.849 loaded highest Eigen Values. Thus the four factors loaded have the following identification.

Factor 1: Success is not only a function of strategy and practice but of the usage of all needed information and knowledge.

Factor 2: Organization leadership should institute a system of project review using the "afteraction reviews" strategy.

Factor 3: Most executive attributes the success of their organization to their own insights and managerial skills and ignore random events or external factors effects.

Factor 4: The more power the Chief Executive acquires by time and by success stories the more solo mind they become.
The leadership style components can be easily interpreted by analyzing the signs and size of the indicators in relation to the new component variable (Table 4).

Four factors identify by factor analysis were used as independent variables while organizational survival was dependent variable.

\subsection{Hypotheses}

The hypotheses for the study are stated using the null hypothesis approach as follows:

(1) $\mathrm{H}^{0}$ : Organizational success is not only a function of strategy and practice but of the usage of all needed information and knowledge by the leader.

(2) $\mathrm{H}^{0}$ : Organization leadership should not institute a system of project review using the "'after-action reviews" strategy.

(3) $\mathrm{H}^{0}$ : Organization leadership (top executives) do not attributes the success of their organization to their own insights and managerial skills ignoring random events or external factors effects.

(4) $\mathrm{H}^{0}$ : The acquisition of more power by the Chief Executive (leader) by time and by success stories do not lead to the leader's solo mindedness

Table 5: Hypothesis testing

\begin{tabular}{ll}
\hline Hypotheses & Asymptotic Sig. \\
\hline Hypothesis 1 & 0.000 \\
Hypothesis 2 & 0.302 \\
Hypothesis 3 & 0.000 \\
Hypothesis 4 & 0.000 \\
\hline
\end{tabular}

Source:

The results revealed that all the selected and tested hypotheses are significant at 0.005 except hypotheses two which was neither significant at 0.010 nor 0.005 level. The null hypothesis formulated will be rejected for hypotheses 1 , 3 and 4 while the null hypotheses will be accepted for hypotheses 2 . The following findings were therefore made:

(1) Organization success is a function of strategy and 
practice but by the organization leader using all and available information and knowledge at the time. This support assertion of

(2) Organization leadership should institute a system of project review using the "after-action reviews" strategy to ensure maximum performance in the organization. Gino(2011) suggested this approach and this study have proved that the "after-action review" strategy is a core factor for maximum result or performance by the leadership of nthe firm.

(3) Most executive attributes the success of their organization to their own insights and managerial skills ignoring the effect of random events or external factors effects within the internal and external environment of the firm Kotter(1996). That managing for change should involve the leader learning and understanding what makes for the success and failure of the firm and not relying on their on skill only

(4) The acquisition of more power by the Chief Executive(leader) by time and by success stories result in the solo mindedness of the leader, this account for the abuse by some of the banks chief executives which lead to the current Central Bank Nigeria sacking five CEOs of the banks. This result is in tandem with the study by Gino (2011) on why leadership of the firm become overbearing and solo-minded with acquisitions of more power in the firm.

(5) The leadership of the organization should celebrate success but examine why they occurred. The top executives of the organization should institute a phase- a- system process of classifying factors that make for success as internal and external factors this also is in agreement with the pervious study by Gino (2011) who theoretically stated this approach for success measurement in the firm by the leadership of the firm

\section{Conclusion and Recommendations}

It should be noted that this study focus on why leaders of firms fail and why they succeed. The study revealed that the top management and leadership's styles, skills and strategies will make for success or failure in the firm depending on the establishment of necessary strategies. It is pertinent to note that failure and success of organization leadership is not a product of power and confidence of the leader it is however absolutely depending on available information and ability to evaluate events within and outside of the firm.

It is thus of value that the leader of the organization should put in place proper mechanism for measure of success, failure and general performance of the firm. Management should also put in place the strategy of measuring performance (success) of the firm. The board of business organization should delimit the power of the CEO by appointing different individual as the CEO and another as the chairman of the firm.

\subsection{Suggestion for Further Study}

The study only covered the relationship between leadership styles and strategy and organization success, however, it does not cover whether organization leadership's skills could be acquired by training or by natural instinct, this is an area other research could focus on

\section{References}

[1] Bass, B and Avolio, B (1994). Improving Organizational Effectiveness through Transformational Leadership. Sage Publications

[2] Cookery for dummies (2011). why Leaders Don't Learn from Success, Harvard Business review, Mar 2011

[3] Duda, R, Hart, P and Stork. D (2001). Pattern Classification. Second Edition, John Wiley \& Sons, Inc.,

[4] David, A Cole(2005). Developing Leaders \& Leadership in Organizations, The Learning Innovations Laboratory (LILA). Harvard Graduate School of Education

[5] Gino, Francesca and Gary, P Pisano(2011). Why leaders don't learn from success. Harvard business review

[6] Haykin, S (1999). A ComprehensiveFoundation. Second Edition. Prentice Hall Inc.

[7] Kotter, J (1996). Leading Change.Harvard Business School Press

[8] Kehinde J S ( 2011). Strategic Financial Management. Lagos: Rakson educational publisher.

[9] Kaiser, H F (1960). The Application of ElectronicComputers to Factor Analysis, Educational and Psychological Measurement, 20, 141-151

[10] Margie Jarvis(2012). Leadership and organization success. Avidus associate ltd. Perkin (2003). King Arthur's Round Table

[11] Stevens J (1986). Applied Multivariate Statistics for the Social Sciences. Hillsdale, NJ: Lawrence Erlbaum Associates.

[12] Quinn Mills D (2005). Leadership: How to Lead, How to Live

[13] Rollinson, D, Broadfield, A \& Edwards, D (1998). Organisational Behaviour and Analysis : An integrated approach ; Addison Wesley Longman, Harlow

[14] Horner Caroline (2002). Executive Coaching:The Leadership Development Tool of theFuture www.btinternet.com 